\title{
30-YEAR LIFE SPAN OF A SPRING CANTILEVER BRIDGE: CASE REPORT
}

J.L. Lui. 30-year life span of a spring cantilever bridge: case report. Annal Dent Univ Malaya 2008; 15(1): 48-54.

\begin{abstract}
Besides other indications, the spring cantilever bridge can solve the difficult clinical problem of providing diastema on either side of a pontic. Unlike the conventional bridges, it has a somewhat controversial design in that the anterior pontic is connected to its retainer on a posterior abutment by a relatively long flexible palatal bar. This paper presents a case report of a spring bridge which fractured due to metal fatigue after 30 years of continued service. Other studies reported a mean life span of 8-10 years for conventional bridges. The advantages of the spring cantilever bridge are also discussed.
\end{abstract}

Key words: spring cantilever bridge; life span; serviceability; bridge fracture; metal fatigue

\section{INTRODUCTION}

The spring cantilever bridge has a somewhat different design from other conventional bridges. Instead of being directly connected to its retainer(s) as in fixed-fixed, fixed-movable or cantilever bridges, it comprises of a pontic which is connected to its retainer by a relatively long flexible palatal connector bar (Figure 1). In short, the spring bridge resembles the cantilever bridge in that it is fixed on only one end; therefore the name 'spring cantilever bridge'. The spring bridge is essentially tissue-supported but abutment tooth-retained. Thus, forces of mastication acting on the pontic are absorbed by the supporting palatal mucoperiosteum and completely dissipitated before they reach the abutment tooth which merely acts to retain the bridge in place.

When diastemata are present between adjacent teeth, the replacement of a missing upper anterior tooth by means of a conventional design bridge is impossible if the patient requests that a diastema be maintained on either side of the pontic. A previous attempt to overcome this problem was the use of gold palatal bar connectors to connect the pontic to the retainers cemented to the abutments on both sides as in a fixed-fixed design(1). With the advent of adhesive dentistry this same design was adopted except that the fitting surfaces of the cast retainers
Case Report

\section{J.L. Lui \\ Professor}

Department of Conservative Dentistry

Faculty of Dentistry

University of Malaya

50603 Kuala Lumpur

Malaysia

Corresponding author: Lui Joo Loon

were etched and resin-cemented(2). More recently, the same modified method involving minimalpreparation of two fixed-fixed and two cantilever resin-retained palatal bar connector bridges were reported(3). As these palatal bar connectors were short, the pontics were rigidly connected to their retainers.

In the spring bridge, the palatal bar is relatively long because the abutment tooth is at some distance from its pontic; a missing anterior tooth may be supported by an abutment in the premolar or molar region. Being long, the palatal bar is flexible and allows 'springing' of 1 to $1 \frac{1}{2} \mathrm{~mm}$ at the incisal edge of the pontic. Besides overcoming the problem of diastemata in bridgework, the spring bridge can also be used in circumstances where the aesthetic demand is of prime consideration or where the teeth on either side of the edentulous anterior space are sound or are unsuitable for use as abutments(4).

In fixed prosthodontic work, besides maintaining health and comfort, restoration of aesthetics and function is of paramount importance; the serviceability and longevity of the prosthesis are within the expectations of the patient for all the time, energy and cost involved. A study reported a mean life span of 10.3 years for fixed prosthodontic restorations with caries accounting for most of the failures(5). Another study reported an even lower mean life span of 8.3 years with $22 \%$ of failure due to caries(6). Other failures cited included porcelain fracture, uncemented restorations, poor aesthetics, defective margins, fractured root/tooth, periodontal diseases/mobility, periapical involvement, fractured connector and others.

It is the purpose of this paper to present a case report of fracture of the palatal bar connector of a spring bridge after a 30 -year service following its issue in early 1977(7). 


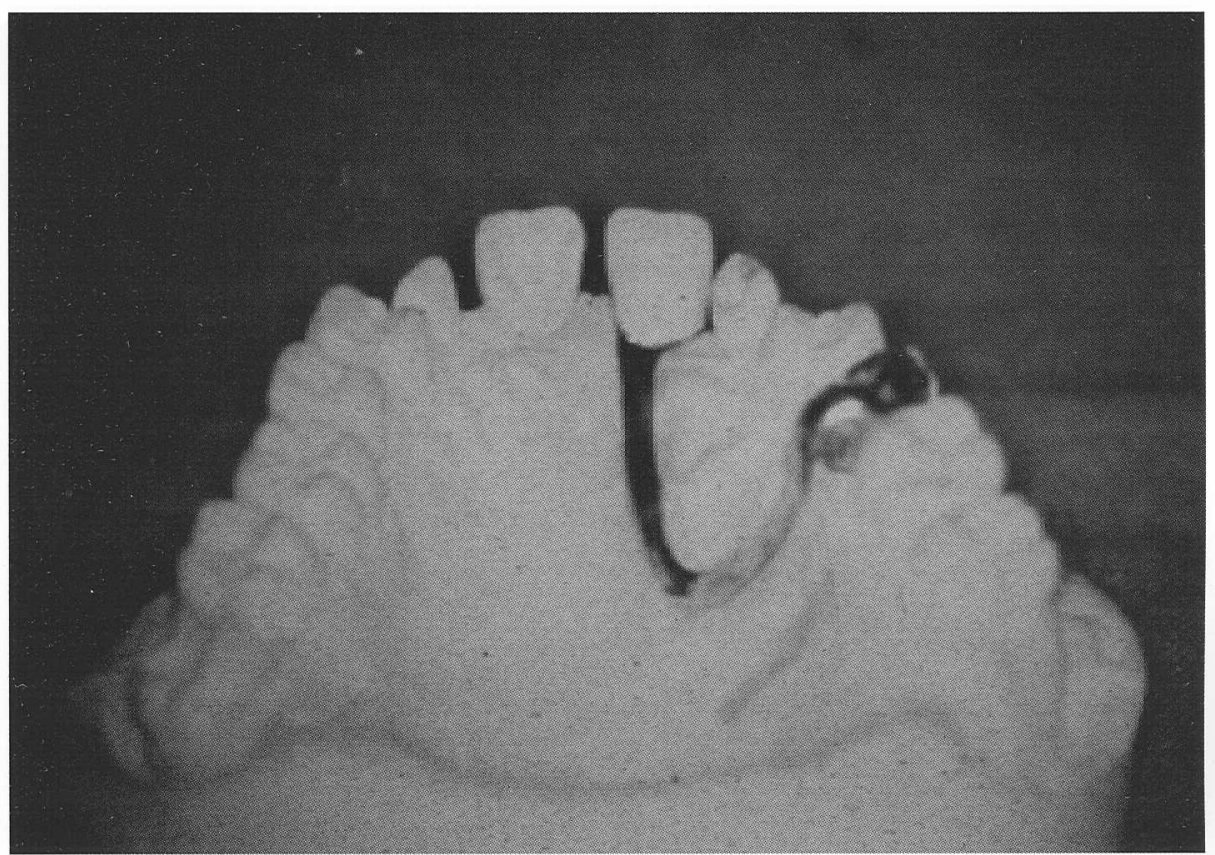

Figure 1: Spring cantilever bridge (In: Dent J Malaysia 1977; 3: 15-20).

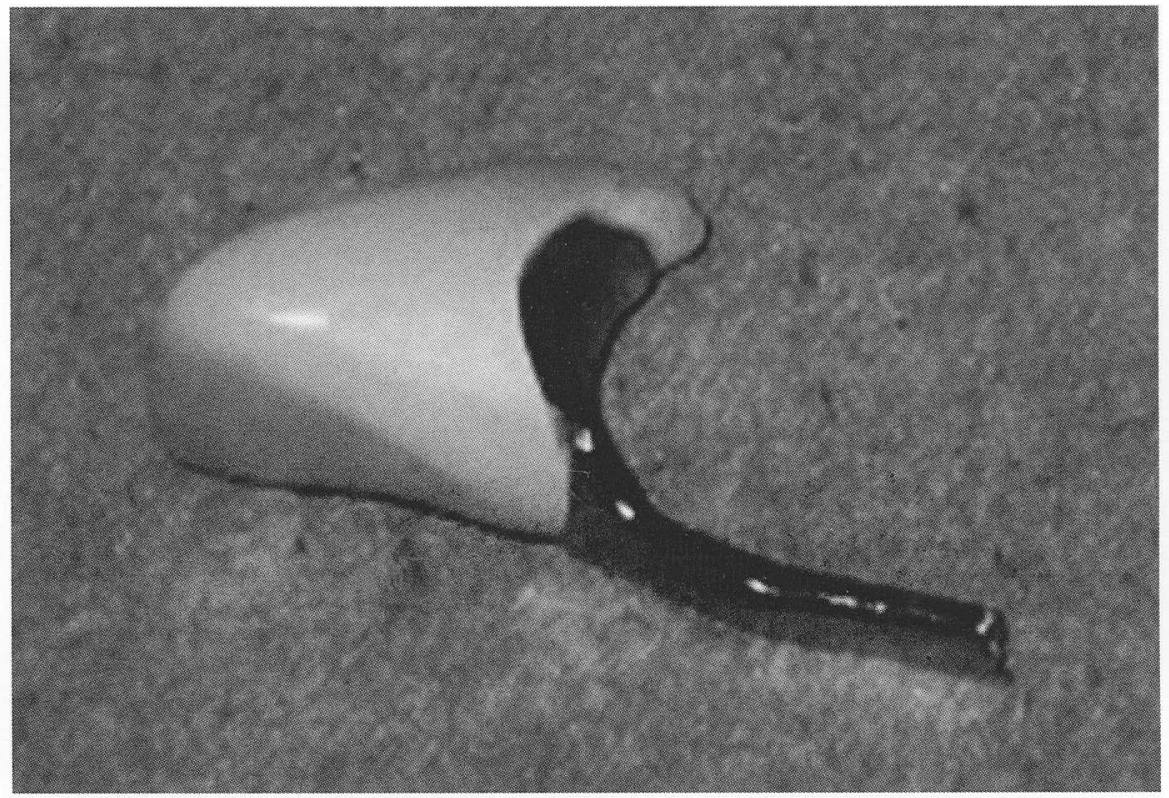

Figure 2: Spring bridge showing detached pontic with anterior portion of the fractured palatal bar.

\section{CASE REPORT}

A 56-year old male Chinese patient returned from Taiwan to the Dental Clinic, Faculty of Dentistry, University of Malaya complaining that his bridge had fractured. He was biting on an apple when he suddenly felt that the pontic portion of his spring bridge was displaced forward and upwards. Instinctively, he pressed the pontic back into place and found that it just dropped onto the floor of his mouth. He brought along the pontic with its attached portion of the fractured connector palatal bar (Figure 2).
The bridge was placed 30 years ago in early January 1977 when he was a 26-year old who had requested for a fixed appliance in place of his loose upper partial denture replacing the upper left central incisor. A spring bridge was indicated for him at that time because of his expressed request to maintain all the diastemata in his mouth; the presence of which were attributed to his congenitally missing upper canines and diminutive upper lateral incisors (Figure 3). There was also some loss of labial alveolar tissues at the edentulous 21 region but he had a low lip line. Following issue of the spring bridge, good oral hygiene was emphasized especially with flossing 


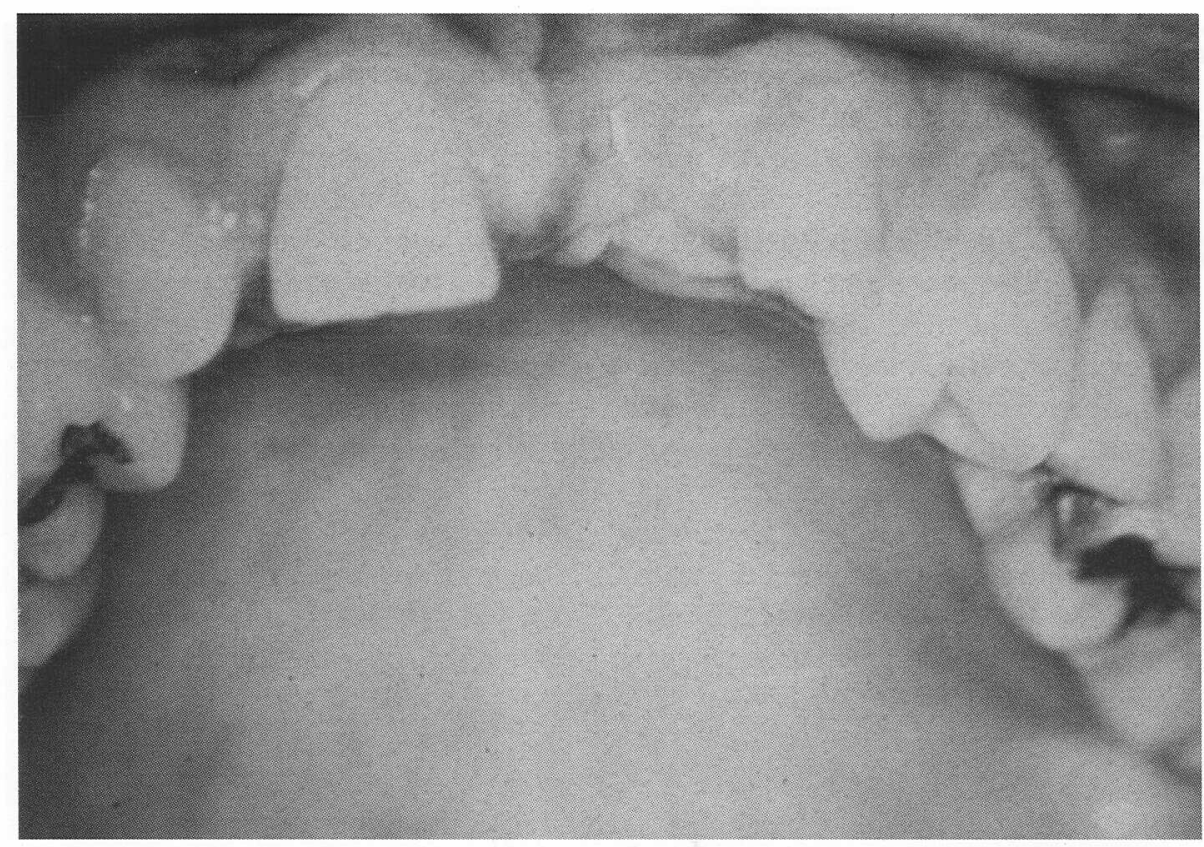

Figure 3: Anterior diastemata present in the upper arch due to congenitally missing canines and diminutive laterals (In: Dent J Malaysia 1977).

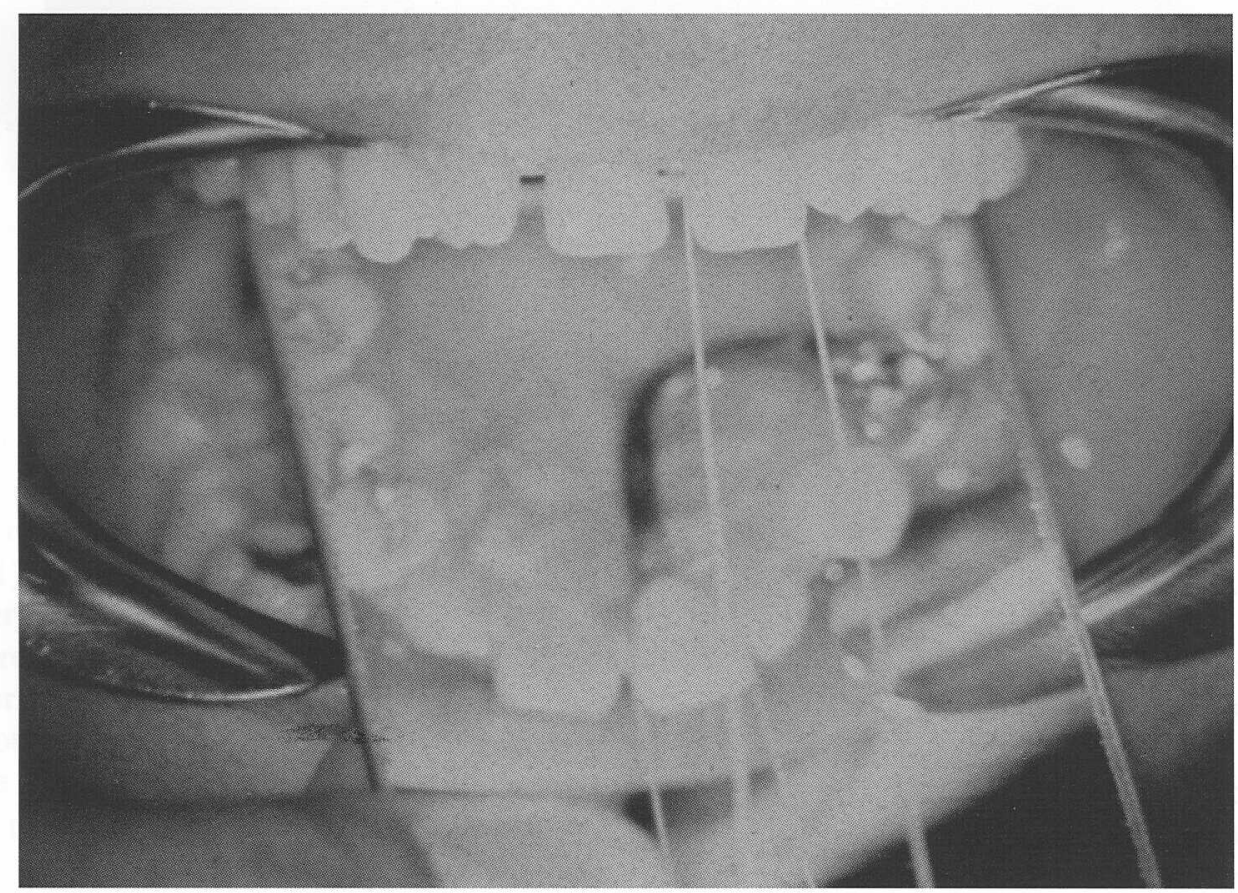

Figure 4: Flossing of the spring bridge.

under the palatal bar (Figure 4) and regular followup reviews (Figures $5 \& 6$ ) were carried out.

The last review was five years ago in 2002 when the bridge was in service for 25 years. There were no untoward sign and symptoms and the general oral hygiene was well maintained. The gingival health around the second upper left premolar abutment was good and no defect was detected at the three-quarter gold crown retainer. The attached palatal bar connector carrying the 21 pontic were all in good condition and the patient had adapted very well to the presence of the palatal bar which had settled onto the mucoperiosteum. The bar still possessed the flexibility to allow 1 to $1 \frac{1}{2} \mathrm{~mm}$ up and down springing action with respect to the pontic incisal edge. The supporting mucosa beneath the pontic and palatal bar was healthy, of normal colour and there was no ulceration. Mechanically, the integrity of the bridge was intact and there was no observable material failure in both porcelain and alloy. Oral 


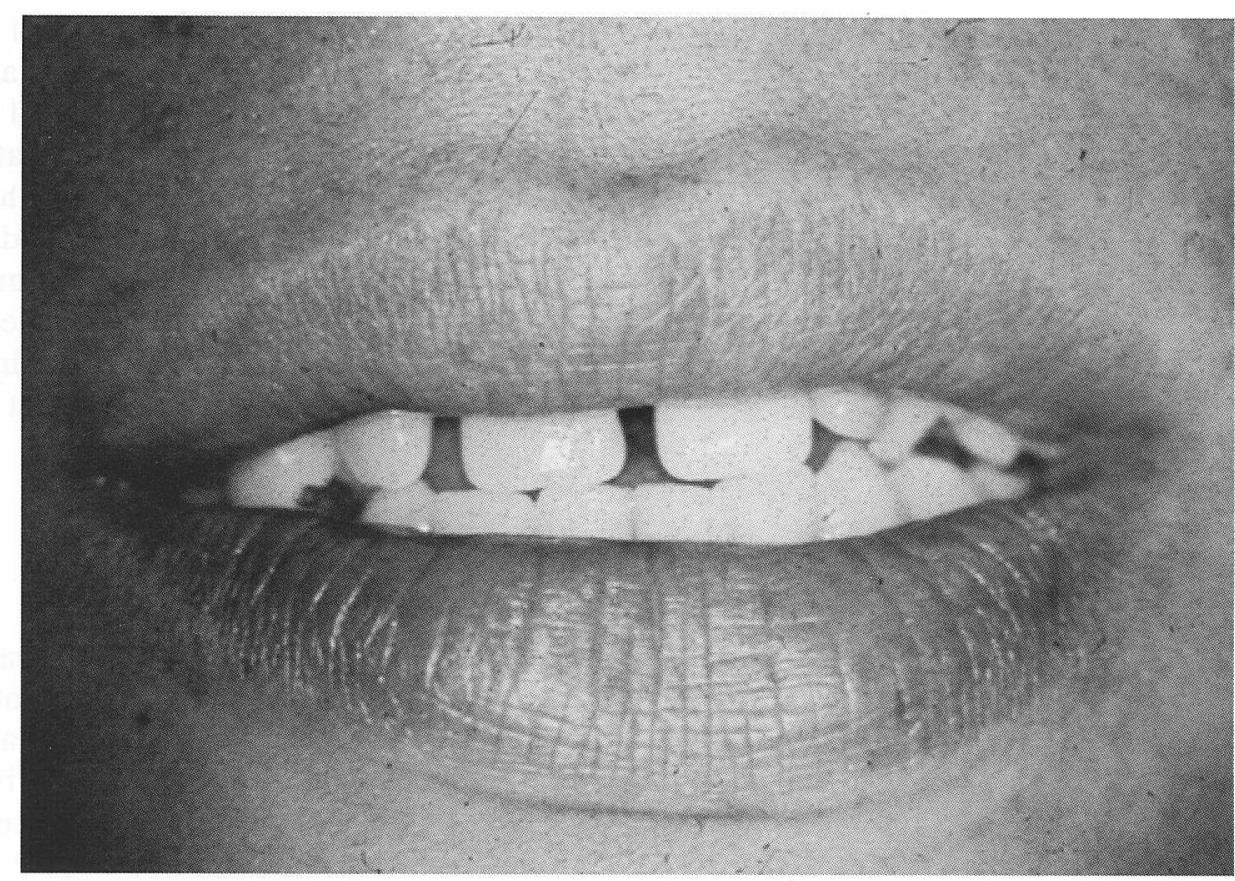

Figure 5: One-week review: the patient was satisfied with the provision of the natural diastemata and the overall aesthetics (In: Dent J Malaysia 1977).

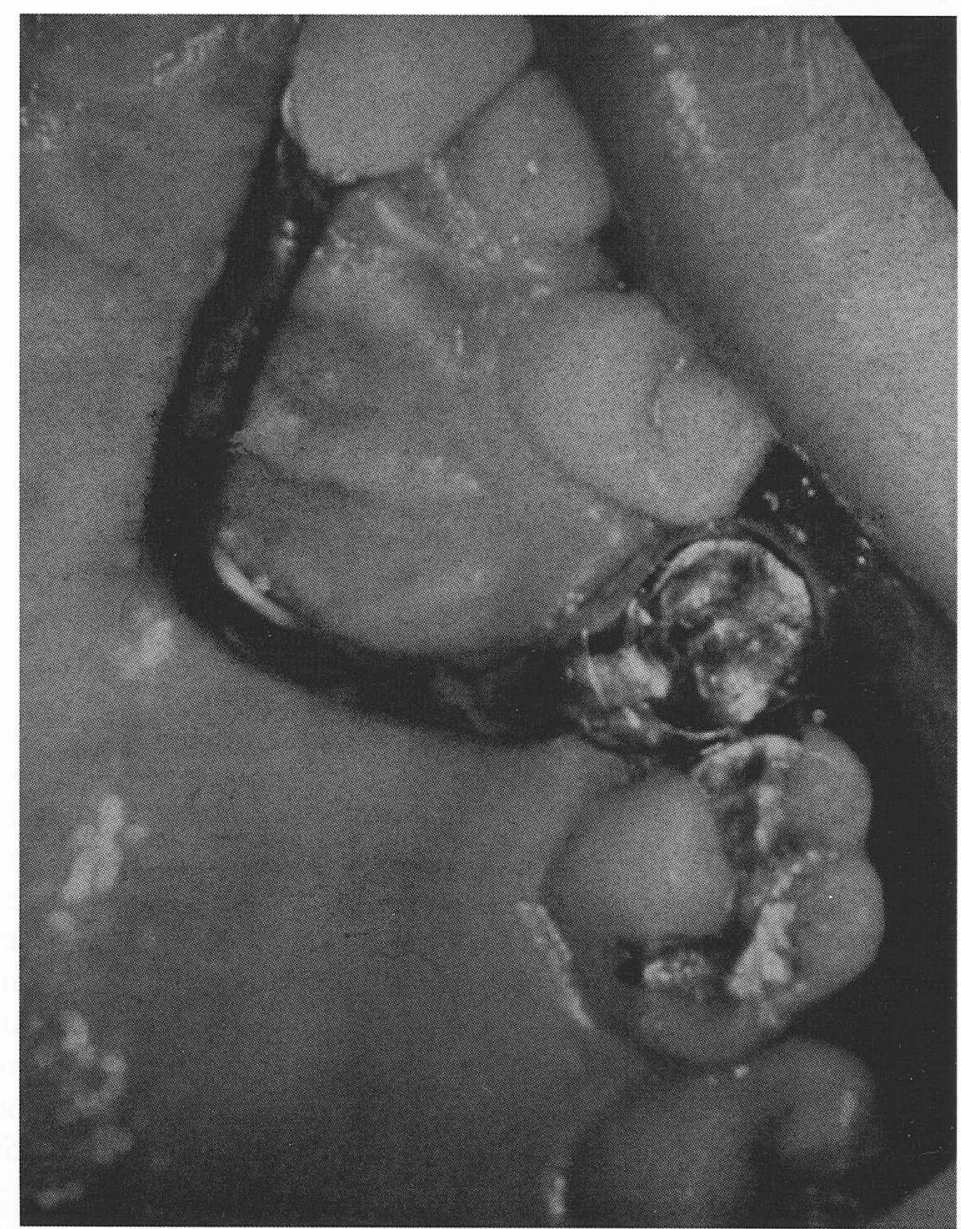

Figure 6: One-year review of the spring cantilever bridge. 
hygiene was reinforced and the patient was dismissed to be reviewed in the next five years at 30 years of service.

Just as the bridge was due for review after 30 years of service, the patient e-mailed from overseas on 14 January 2007 to inform of its fracture and requested attention upon his immediate return a few days later. On examination, the palatal bar had fractured at the straight portion from the pontic leading towards the curved part as the bar turned towards the retainer. Except for the fracture, the detached portion of the bar and the porcelain pontic were in good condition. The remaining portion of the bar was still attached to its retainer and both were also found to be in good condition (Figure 7). The palatal mucosa and the gingiva at the abutment appeared healthy and the abutment tooth was firm and there was no mobility. The retainer was still in piace and was well cemented. The apposing fractured ends of the bar appeared clean and there was no fragmentation.

Various treatment options including partial dentures, bridges, implants and integrated fixed removable prostheses incorporating precision attachments were discussed with the patient. As an interim measure, the still attached portion of the bridge was removed by cutting the three-quarter crown with a water-cooled transmetal bur and the abutment protected by cementing a temporary acrylic crown. An intermediate partial denture was issued within a matter of days so that the patient could presentably continue with his overseas assignments. When the patient returned two months later and after thinking long and hard, he again opted for the spring bridge which he deemed best in his circumstance and banked on the hope that the new spring cantilever bridge would last him another 30 years (Figure 8 ).

\section{DISCUSSION}

This spring bridge which lasted 30 years had a life span three to almost four times that of other fixed bridges reported $(5,6)$. A meta-analysis of 42 publications on conventional bridges between 1970 and 1992 covering 4118 bridges showed an overall survival rate of $74 \%$ after 15 years(8). Though the spring bridge is a controversial prosthesis in that an area of mucosa is permanently covered by the rather long flexible palatal bar, when judiciously indicated and well maintained, it can provide many years of continued service functionally and aesthetically.

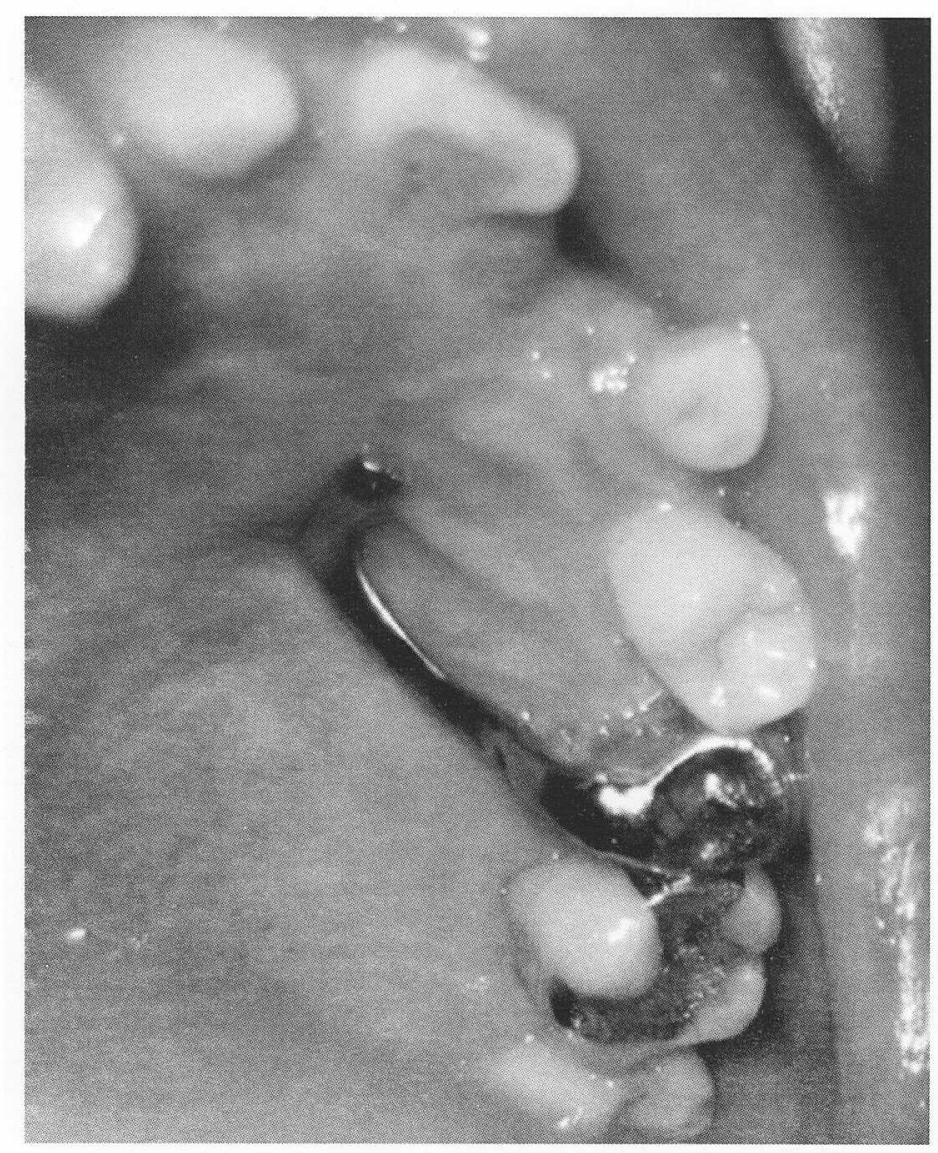

Figure 7: Spring bridge showing cemented three-quarter crown retainer with the posterior portion of the fractured palatal bar still in place. 


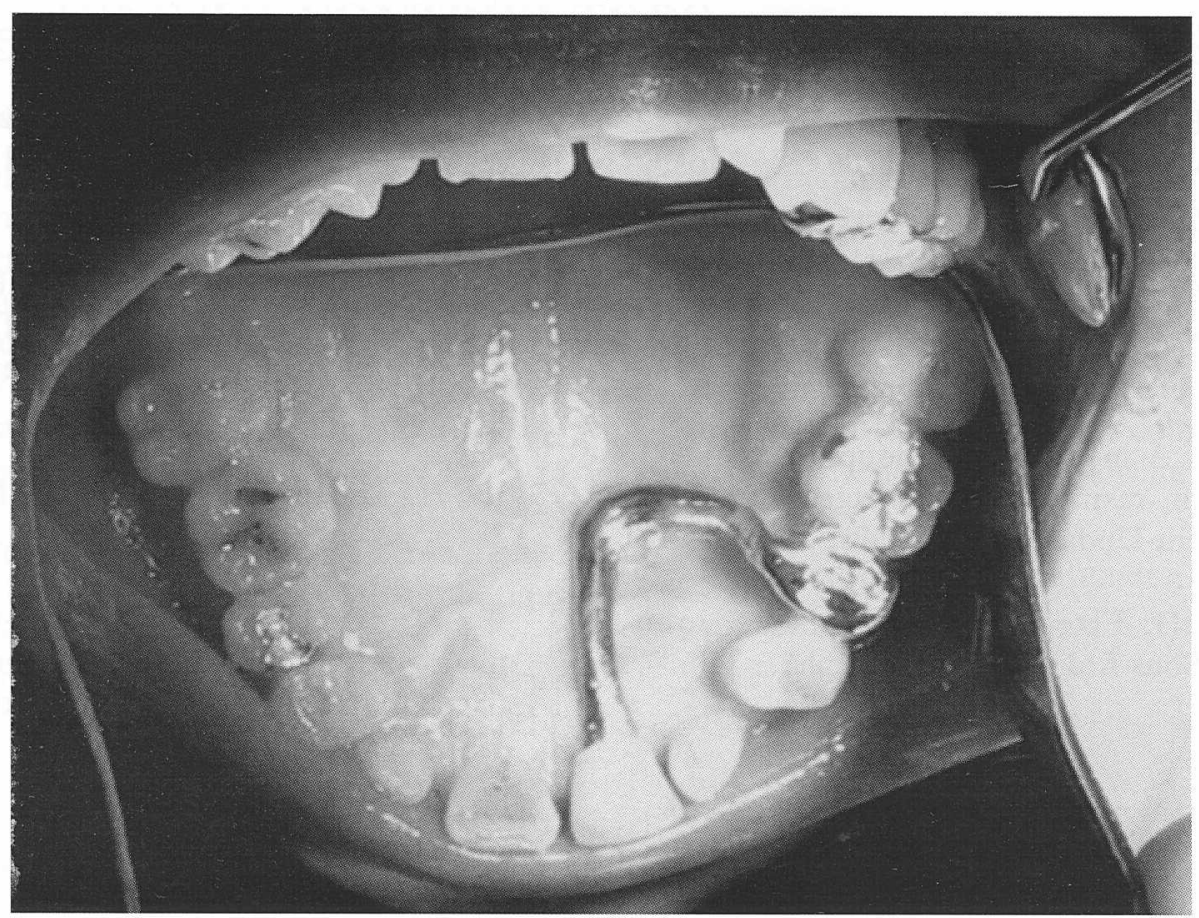

Figure 8: Mirror view of new spring bridge after 1-week post-cementation.

When a diastema is required on either side of the pontic, the spring bridge is the answer as its retainer is placed on a posterior abutment and not connected to the adjacent teeth. The spring bridge can also be indicated if the adjacent teeth to the edentulous anterior space are not suitable as abutments; such as (a) small conical peg-shaped clinical crowns providing reduced retention, (b) small root surface area and/or poor periodontal condition rendering them incapable of carrying the extra load, (c) good sound adjacent anterior teeth which are not justifiable to be mutilated. The spring bridge is not indicated in the lower jaw as the mucosa here is thinner, the shape of the jaw will have the bar coming close to the gingival margins, the bar will not be supported by the mucosal tissue as the bite is generally reverse and there is a greater tendency for calculus formation.

To solve the problem of maintaining a diastema on either side of the pontic, two palatal bars running from the pontic to the adjacent retainers on both sides had been designed(1). This design was further modified with the use of minimal preparation resinbonded retainers(2) and also as in both fixed-fixed and cantilever resin-retained bridges(3). Since these pontics were connected to their adjacent abutment teeth, the connector bars placed on the palatal mucosae were short and stiff. These would be bulky and uncomfortable for the patients. For the spring bridge, the palatal bar is embedded in palatal mucoperiosteum to a depth of $1 \frac{1}{2}$ to $2 \mathrm{~mm}$ clinically by cutting the palatal surface of the working model to half the depth of a No. 10 round bur following the proposed line of the bar and waxing the bar in its embedded position. For all the 30 years of continued service, the patient did not experience any discomfort from the palatal bar. To give a better line to the bar, the abutment of choice for replacing the upper central or lateral incisor is the first or second premolar and as to the canine, the upper first molar is the preferred abutment. The portion of the bar which runs straight back from the pontic to the bend is the tissue bearing portion and it absorbs most of the masticatory forces(7).

The advantages of a spring bridge include: (a) readily achieved aesthetics, (b) relatively short clinical chairside time, (c) provision of diastema on either side of the pontic, (d) usually only one posterior abutment is required to support the bridge and (e) the flexible palatal bar acting as a shock absorber reduces the chances of pontic ceramic from fracturing. The flexible palatal connector bar of the spring bridge, as reported, finally fractured from metal fatigue after 30 years of continuous service.

\section{SUMMARY}

The spring bridge when judiciously indicated and well designed was able to satisfy the demands of the patient to preserve the personal feature of diastemata. Good oral hygiene, patient motivation and regular follow-up reviews contributed to an impressive life span of 30 years which far exceeded most mean life span of other conventional bridges. 


\section{REFERENCES}

1. Myers GE. Textbook of crown and bridge prosthodontics. Saint Louis. The C V Mosby Company. 1969; pp.147-8.

2. McCann KJ. The use of a cast etch bridge in a diastema situation. J Can Dent Assoc 1987; 9: 687-9.

3. Gibson CJ. A modified technique for minimalpreparation, resin-retained bridges: four case reports. Dent Update 2001; 28: 442-8.

4. Roberts DH. Fixed bridge prostheses. John Wright \& Sons Ltd, Bristol. 1973; pp. 165-76.
5. Schwartz NL, Whitsett LD, Berry TG, Stewart JL. Unserviceable crowns and fixed Partial dentures: Life span and causes for loss of serviceability. J Am Dent Assoc 1970; 81: 1395401.

6. Walton JN, Gardner FM, Agar JR. A survey of crown and fixed partial denture failures: length of service and reasons for replacement. J Prosthet Dent 1986; 56: 416-20.

7. Lui JL. The spring bridge. Dent J Malaysia 1977; 3: $15-20$.

8. Creugers NHJ, Kayser AF, van-t Hof MA. A meta-analysis of durability data on conventional fixed bridges. Community Dent oral Epidemiol 1994; 22: 448-52. 


\section{INSTRUCTIONS TO CONTRIBUTORS}

\section{GENERAL INFORMATION}

The Annals of Dentistry University of Malaya is published annually as the official journal of the Faculty of Dentistry, University of Malaya, Kuala Lumpur, Malaysia. As a general guideline, articles intended for publication in the following year should be received by the Editor by the end of December of the preceding year. Original research articles and critical reviews, pertaining to dentistry and its allied fields will be considered for publication at the discretion of the editors. Articles will be refereed independently by at least two referees. Contributions from all sources including from international contributors are welcomed. The following guidelines must be strictly adhered to by intending contributors.

\section{GENERAL INSTRUCTIONS}

All contributions must be in English (Concise Oxford Dictionary). Authors should submit three copies of the manuscripts (one original and two copies) along with three sets of illustrations and figures. The submitted manuscripts must be accompanied by a covering letter which includes: (a) information on prior or duplicate publication or submission elsewhere of any part of the work, (b) the name, address, telephone number and e-mail address of the corresponding author responsible for communicating with other authors regarding revisions and final approval of the proofs, and (c) whether the author(s) are willing to meet the cost of reproducing colour illustrations (if any). The author who sends the article is responsible, in obtaining all the authors agreement to publish and include in the letter a statement "I am submitting this paper, which has been approved by all authors". The manuscript must also be accompanied by a letter of permission to reproduce published material or to use illustrations other than the authors of the manuscript submitted. The editorial board reserves the right to edit all manuscripts for conciseness, clarity and stylistic consistency. Manuscripts are refereed anonymously. Authors must keep copies of manuscripts sent.

\section{CORRESPONDENCE}

Address all correspondence to: The Editor, Annals of Dentistry University of Malaya, Faculty of Dentistry, University of Malaya, 50603 Kuala Lumpur, Malaysia. Please include your e-mail address.

\section{SUMMARY OF REQUIREMENT}

Type the manuscript on white bond paper, 216 by $279 \mathrm{~mm}$ or ISO A4 $(212 \mathrm{~mm}$ by $279 \mathrm{~mm})$, with margins of at least $25 \mathrm{~mm}$. Type only on one side of the paper. Use double spacing throughout. Number pages consecutively beginning with the title page. Type the page number in the upper right hand corner of each page. Each manuscript component should begin on a new page in the following sequence:

Title page

Abstract, Key words \& Running title

Text \& Acknowledgements

References

Tables

Illustrations

\section{TITLE PAGE}

This should carry: (1) Title of the article which should be concise but informative, (2) Initials and last name of each author, (3) Institutional affiliation, (4) Name of department and institution should be clearly stated, (5) Name, postal address, telephone number and e-mail address of corresponding author.

\section{ABSTRACT, KEY WORDS \& RUNNING TITLE}

The second page should carry an abstract of not more than 250 words and should state the purpose of the study or investigation, basic procedures, main findings and principal conclusions. Below the abstract, provide and identify in not more than 10 words the key issues of the article. Also, include a short running title at the bottom of the page.

\section{TEXT}

The main text should include: Introduction, Materials and Method, Results, Discussion, Conclusion, Acknowledgements (if any) and References, in that order respectively.

\section{INTRODUCTION}

Begin with a concise introduction by outlining the purpose of the research and making reference to previous relevant publications. Mention any limitation or gap in existing knowledge related to the study in question. Do not review the subject extensively and do not include data or conclusion from the work reported. 


\section{MATERIALS AND METHOD}

Describe precisely the materials/subjects used. Identify the methods, apparatus and procedures used in sufficient detail so as to allow other workers to replicate the study. Give references to established methods, including statistical methods. Provide references and brief descriptions for methods that have been published but are not well known. Describe new or modified methods and give reasons for using them and evaluate their limitations. Identify all drugs and chemicals used including generic names, dose and route of administration.

\section{RESULTS}

Present results in a logical sequence in the text, tables and illustrations. Do not repeat in the text all the data in the tables and illustrations. Emphasise or summarise only important observations. Specify statistical methods used to analyse results and describe them with sufficient detail to enable a knowledgeable reader with access to original data to analyse results.

\section{DISCUSSION}

Emphasise the new and important aspects of the study and the conclusion that follow from them. Do not repeat in detail, data or other materials, given in Introduction or Results section. Include in the Discussion section the implication of the findings and their limitations, including implications for future research. Relate the observations to other relevant studies.

\section{CONCLUSIONS}

Link the conclusions to the goal of the study but avoid unqualified statements and conclusions not supported by your data.

\section{ACKNOWLEDGEMENTS}

Acknowledgements where applicable should be included at the end of the text. This should be kept to a minimum.

\section{REFERENCES}

References should be carefully checked, as their accuracy is the responsibility of the author(s). In the text, references should be numbered sequentially in order of citation by bracketed numerals, eg. (1,3-6). The reference list must be attached at the end of the paper using the following format:

\section{Journals:}

1) Master M, Barber TK. Action of amalgam on dentin. J Am Dent Assoc 1980; 47: 415-22.

2) Murray AJ, Nanos JA, Fontenot RE. Compressive strength of glass ionomer with and without silver alloy. J Dent Res (Abstract no: 215) 1986; 65: 193.

3) Kato Y, Okawa A, Hayashi S, et al. Studies on marginal leakage of composite resin restorations. Part 2: On the leakage properties of various composite resin restorations. Jpn J Conserv Dent 1976; 19: 281-9.

4) Klineberg IJ, Murray GM. Design of superstructures for osseointegrated fixtures. Swed Dent J 1985; 28(Supp1): 63-9.

5) Lincks J, Boyan BD, Cochran DL, Liu Y, Blanchard C, Dean DD, Schwartz Z. MG63 cells discriminate between surface roughness and material composition. J Dent Res (Abstract no: 1123) 1998; 77 (Special issue A): 246.

\section{Books, Monographs and Agency Publications:}

Book - Chapter in a book:

1) Zinner ID. Esthetic considerations in restorative dentistry. In Seide LJ, ed. A dynamic approach to restorative dentistry. 1st edn. Chicago, W.B. Saunders Company 1980; pp. 520-58.

Book - personal author/s:

2) Gutmann J, Harrison JW. Surgical Endodontics, $1^{\text {st }}$ edn. Boston, Blackwell Scientific Publications 1991.

Monograph - Book Proceeding:

3) DuPont B. Bone marrow transplantation in severe combined immunodeficiency with an unrelated MLC compatible donor. In: White HJ, Smith R, eds. Proceedings of the third Annual Meeting of the International Society for Experimental Hematology 1974; pp. 44-6.

Monograph - thesis/dissertation:

4) Tay WM. Physico-chemical properties of aluminosilicate based dental cements. University of London, 1988. PhD. thesis.

Agency publication:

5) Parkin DM, Whelan SL, Ferlay J, Raymond L, Young J. Cancer Incidence in five continents. Volume VII, International Agency for Research on Cancer: Lyon. IARC Scientific Publication No 143. 1997. 


\section{Tables:}

Each table should be typed on a separate sheet, numbered consecutively in Arabic numerals (eg. Table 4) and titled with a descriptive but concise heading. Explanatory notes if any should be placed below the table.

\section{Illustrations:}

All graphs, drawings and photographs are considered figures which must be of good quality usually 127 by $173 \mathrm{~mm}$ ( 5 by 7 ins) but not larger than 203 by $254 \mathrm{~mm}$ ( 8 by 10 ins). Submit 3 copies in a heavy-paper envelope. Authors must keep copies of everything submitted. At the back of each illustration, label the appropriate Figure number corresponding to the order of appearance as cited in the Text. Use a soft pencil to indicate the top of the illustration and lightly write in the running title. The author's name should not be added. Original drawings, figures, charts and graphs should be professionally drawn and lettered large enough to be read after reduction. High quality computer generated line diagrams or glossy prints are also acceptable. Photographs in general should be clear black-and-white prints on glossy paper. Colour illustrations may be submitted if they contribute to the value of the article but the full cost of printing must be borne by the author(s). Prints of radiographs should be sharp and clear. Photomicrographs must include a scale and magnification should be clear. Consent must be submitted with the manuscript.

\section{Legends:}

Each figure must have a legend that is clear without reference to the text. All legends should be typed on a single sheet with the corresponding figure number clearly indicated.

\section{Figures and Tables in the text:}

Figures and tables should be spelt out in full when referred to in the text e.g. Figure 2 or Table 3. 